\title{
Some Considerations \\ on the Activity of Insurance Business \\ and its Relevance for a General Reassessment \\ of Economic Theory *
}

by Orio Giarini **

\section{Introduction}

These "considerations" are put forward with a view to the discussion of the following major points :

- the idea that economics is still essentially the intellectual offspring of the "classical" industrial revolution : if we really live in a "post-industrial" society, it follows that some basic paradigms - in particular, the notion of value - have to be radically reconsidered (sections 2 and 3 );

- this rethinking of basic economic notions, like all such revision, is related to a wider cultural background and in particular to the definition of science and its value to society as a means of improving knowledge ; it is maintained that economics is still largely anchored to the definition of science that prevailed until the beginning of the twentieth century (positivist, Newtonian). As such, it favours a static notion of time and space as well as models based on the certainty assumption.

Insurance activity, properly analyzed from an economic point of view, needs a real (dynamic) space/time dimension and the substitution of the certainty assumption

* The ideas summarized here are discussed at greater length in Dialogue on Wealth and Welfare - a Report to the Club of Rome (Oxford, Pergamon Press, 1980, 380 pages). French edition : Dialogue sur la Richesse et le Bien-Etre (Paris, Economica, 1981); Italian edition : Dialogo sulla Ricchezza e il Benessere (Milano, Mondadori-EST, 1981) ; Japanese edition by Diamond, Tokyo, 1981.

This paper was originally presented at the seventh Seminar of the European Group of Risk and Insurance Economists, University of Nottingham, September 1980. The author is also indebted to Peter Franklin and Henri Loubergé for their helpful remarks and suggestions. Neither of them is, however, responsible for the views expressed or any errors therein.

** Member of the Club of Rome. 
by that of uncertainty. The integration of insurance activity in a general economic theory coincides with the integration of basic economic notions in, and their adaptation to, current scientific thinking (section 4);

- at the level of industrial practice, it is noted that the success of the notion of " risk management" is the result of the change from an essentially "industrial" society to a "post-industrial " one. In the first, the top management is exclusively concerned with the "entrepreneurial" risks ; in the latter, the " pure" risks (or vulnerability) become as important for the general management as the "entrepreneurial" risks, and both are very often largely interdependent (section 5);

- the success of economics in the future will depend very much on the possibility of including uncertainty (and real time) in its models, theories and empirical research. This will give insurance a higher "status" as an economic activity (section 6).

In two appendices, it is proposed to consider a "dynamic" notion of economic value and an overview of the major characteristics of the big cycle of the industrial revolution.

\section{Economics and the economy}

The economy defines that part of human activity devoted to the production and consumption of wealth and the promotion of welfare. As such, it is concerned with the identification, invention and utilization of resources that are both material and cultural. Explicitly or implicitly, the purpose of such activity includes goals of a general and a particular nature, such as survival and the enjoyment of life in the broadest sense.

Economics is in principle concerned with that set of coherent theories aimed at providing a consistent insight into the way the economy behaves. Such consistency is normally proved by the capacity of the theory (or model) to provide useful and usable predictions of such behaviour in global terms (macroeconomics) or in specific and sectorial terms (microeconomics).

It is obvious that economic activity runs parallel to human history. The manufacture and use of tools by prehistoric man was already indicative of a capacity to divert labour from the production of consumption goods to capital goods and to develop newer technologies and know-how even in the complete absence of money.

Observations and even embryonic economic theories can be found in most ancient literatures. But they are normally diluted within the general description of society.

It is generally accepted that economics as a specific discipline or science took definite shape in 1776, when Adam Smith published his book The Wealth of Nations. As Alfred Marshall put it, " his chief work was to find in the theory of value a common centre that gave unity to economic science" ([10], p. 627). This unity was consistent both with historical facts and with the cultural paradigms or principles of the European culture of his time. The main fact was the birth of a great period of economic development known as the industrial revolution, based on three major interdependent factors : 
a) the development of the industrial mode of production to such an extent that it became, for the first time in history, the first and decisive factor in the production of wealth and the basis of power. Contrary to Quesnay, who still described wealth as essentially dependent on agriculture, Adam Smith detected, from his personal empirical observations during a couple of dozen years of the first stages of industrialization (at that time still a very minute phenomenon), the grounds on which the wealth of nations would be built ;

b) the development of new technologies and the technical means of using them, through a process of concentration (economies of scale) and specialization ;

c) the monetarization of the economy to an unprecedented extent. Ivan Illich [8] has calculated that in the 16th and 17th centuries in Europa only 1 per cent of the average lifetime of a European person was dedicated to remunerated work. In our time, this percentage would be around 16 per cent. This means that if money has always been used, it is only since the industrial revolution that its quantity and circulation have become of real general economic relevance. The monetarization of the economy is the premise that allows capital formation : the accumulation of means and power through money becomes more and more important. This accumulation is the condition that permits the use of more and more concentrated (and expensive) technologies; it is the best solution to an obvious logistic problem, one which made it impossible for the industrial revolution to have started earlier (most of the technologies of the first industrial revolution were almost within reach already before the fall of the Roman Empire).

\section{Economics as a theory of the industrialisation process}

It is important, in our view, not to underestimate the fact that economics itself is a consequence of the birth of the industrial revolution. For Adam Smith it is clear that the real productive value which adds to wealth is the one emanating from what we now call industrialization or the industrial mode of production.

A lot of improductive value is produced, or unproductive labour performed, in society, by activities such as those we now call services or the tertiary sector (doctors, lawyers, financial services, insurance). 1

In other words, the specialization of economics is such that it tends in fact to concentrate from the beginning on the industrialization process. The notion of value itself selects what will or will not enter into the analytical models.

But such selection is not only a matter of personal preferences : if it had been, it might have changed after Adam Smith. On the contrary, with time, this selection

1 "The labour of some of the most respectable orders in the society is, like that of the menial servants, unproductive of any value ... the officers of justice ... the army ... protection, security,... churchmen, lawyers, physicians, men of letters of all kinds ... buffoons ... opera singers ... (A. Smith [16], pp. 430-443). 
has become more and more precise, for much more deep-seated reasons. Some of these stem from the very basis of European philosophy.

In order to found a new discipline " scientifically", it was not sufficient, and it is still not always sufficient, to provide a verbal definition. To be "scientific", a theory must be verifiable and "facts" have to be measurable. It is on this point that Adam Smith provided the definitive foundation of economics : the notion of value quantified through the price system. The market system (the "invisible hand"), through the supply and demand law, establishes a price, in order to remunerate the value produced by man. At this point, a series of important comments should be made :

- The importance of the "invisible hand" lies primarily in the fact that it suggests the idea that price is an "objective" measurement. This aspect is much more important than the interpretation of the notion of the "invisible hand" as a fundamental plea for economic liberalism. This is only partly true. It is the "objectivity" side of it which really matters and opens the door to the "scientific" pretensions of economics in all "political" directions. It is not really an accident that Marx was to a great extent a follower of Adam Smith (the invisible hand depends for Marx on another "objectivist" concept : the class struggle. The search for objectivity has the same philosophical foundation).

- Thanks to the tool provided by quantifiable (priced) values, economists have hoped to become as "scientific" as researchers in the natural sciences, who can largely determine the systems or models they analyze through the measurement of specific factors (heat, speed, weight, inertia, resistence, wave-length, etc.). ${ }^{2}$

- If priced values are the key to economic analysis, then economics must centre almost exclusively on monetarized production and consumption systems. Although traditional economists still write extensively about non-monetarized utility values, they will with time abandon this notion, on the one hand because they work more and more on the assumption that what is "free" is not scarce and therefore place it outside the economists' pale (which in our view is largely wrong), and on the other because they see no way of measuring them properly (because of their implicit Cartesian premises). Other economists have tried to broaden the spectrum of economics by introducing the notion of "shadow" prices to account for some of the now monetarized values : in our view, this procedure is of limited interest because the problem today is not one of fitting the facts of the economy to existing economic theory at any price, but of verifying in depth whether the fundamental question of how to create values that increase the wealth of nations can find consistent answers within a theoretical framework constructed for the most part on the basis of facts and cultural or philosophical backgrounds different from those existing today.

- It is indeed obvious that the notion of priced or monetarized values is necessarily linked to the situation of a developing economy where exchanges and production

2 In point of fact, most economists today still assume as given a notion of science that is fundamentally positivist, and do not go beyond Newtonian concepts. See Mayer [11] : this article is written without any explicit reference to what hard science is today in the natural sciences, and physics in particular. See by contrast Weisskopf [17]. 
follow the monetarized pattern. As we have already stressed, it was precisely during the birth and development of the industrial revolution that the wide diffusion of the monetarized system took place. But even in the time of Adam Smith, only very limited use was made of money in the economic activities relating to production and consumption compared with its use in these activities today. We should note here the great confusion that usually prevails between the stories written about money (its origin and use) and the question of the transition of economic activities from a non-monetarized to a monetarized pattern. A key question today is that of the equilibrium between the two systems. ${ }^{3}$

- The reason for the decisive growth of monetarization during the industrial revolution is closely linked to another fundamental factor : the development of modern technology. The more "modern" the technology, the more costly it is, which means that more " capital " (accumulated money) is required. In order to accumulate money efficiently, the economic system must be increasingly monetarized. During the eighteenth century the "capital requirements" in England were, as Adam Smith said, much higher than ever before in history (up to a maximum 5-6\% of sales...). This percentage reached $12-15 \%$ in the last century and 25 and $30 \%$ in our time.

Industrialization therefore is essentially the history of technological development and capital requirements, of specialisation and of monetarization. A society which is not monetarization-prone has much greater difficulty in using and benefiting from modern technology, as this has evolved in Europe.

- Adam Smith therefore, centering his attention on development and industrialization and founding his economic analysis on the notion of priced value, hit the focal point of economic history during the two subsequent centuries.

- We can only stress the extent to which all these factors are synergically interrelated and correspond to a Cartesian view of logic (rationalism), which in the historical period of the industrial revolution fits fairly well with actual facts. Wealth and welfare henceforth grow in unprecedented proportions.

The process of economic development has been centered up to recent times on industrialization : economics itself has become essentially a discipline of this process, and not of all the factors contributing to material wealth and welfare. But this reductionist view has been effective in any case because the over-all result in wealth and welfare is impressive. Our hypothesis is that the key reason for this success was the availability for more than two centuries of a long-term cycle of increasing returns on technology. 4

In this context, it should be noted that the priority given to industrialization is evident in the way economic (monetarized) activity is still divided, even today, into the primary (agricultural), industrial and tertiary sectors. There has always been great difficulty, throughout two centuries of industrial revolution in adapting agriculture to

3 See Giarini [4], chap. 3.

4 See Giarini and Loubergé [5]. 
industrial development, for the simple reason that its economic structure, at least in the initial stages of the process, was essentially non-monetarized, and therefore economically undervalued by the new paradigm focussing on monetarized activities.

The tertiary sector includes a quantity of services of which some are "valued" today and others are not (in terms of GNP accounting). In any case, this was a "residual" category of little "economic" interest at the beginning of the industrialization process. Even today, it is interesting to note in the input-output models how the tertiary and in particular the services sectors are still a " residual " part of the model.

One of the key points that it is important to understand when speaking of structural changes in our present economic situation is that the reality of "post-industrial " or "service" economics is not one in which the tertiary sector has evolved (as various statistics often show). The key to the phenomenon does not lie in the growth of this latter sector at the expense of the other two. The subdivision is no longer vertical : it is horizontal. On the one hand, both agriculture and services use machinery and capital equipment typical of industrialized activities. On the other hand, the industrialized sectors themselves make increasing use of "service-type" functions, which are very often of the kind termed " unproductive" by traditional economists (although they still employ the greater part of the labour force).$^{5}$

In our view, it is therefore absolutely inadequate and highly misleading to accept, on the one hand, the idea of the importance of the "services sector" in our society and, on the other, to continue classifying this phenomenon with tools which correspond to largely obsolete circumstances.

The reason why old methods are still applitd, even if admittedly inconsistent with present economic reality, is that little revision has been carried out at the level of the basic notions at the origin of economic analytical methods. ${ }^{6}$

\section{Economic theory, services and insurance}

It is our thesis that economics, developed as a discipline or a science since the time of Adam Smith, is essentially the theory of the industrialization process in so far as this process represents the essential or even the exclusive contribution by man to

5 See the second chapter in Giarini [4].

6 It is also our opinion that although the notion of value is no longer production oriented (as in classical economics) but subjective (demand oriented), as developed by neoclassical economists, the underlying Cartesian/industrialist assumptions of the general economic model remain virtually unchanged. Worse still, the subjective value theory is making it more and more difficult, in many respects, for economics to be a helpful discipline in defining and organizing the factors of production at the present time. What is badly needed today is a new, post-industrial notion of value, on the supply side. 
the increase in the wealth of nations. From this angle, all phenomena not part of the industrial mode of production proper are secondary, or considered to be so both in practice and in theory. In our view, this remains true even if the history of economic thinking has changed greatly since Adam Smith, and even if it has come to embrace ever wider horizons. Indeed, even when, in many cases, economics has tried to go beyond the industrialization process proper, it has always considered this to be the reference for any other type of activity. Through shadow-price systems, or by analyzing the value of services, economics has always tried to bring analysis back to the industrial "paradigm" as its basic reference. In other words, we consider that "economics" today is less and less related to the "economy", i.e. to the way in which wealth and welfare are today really produced and made available.

The roots of this situation have to be sought in the inadequate verification of the extent to which present economic theories, derived from more general scientific axioms and philosophical principles, correspond to present epistemological conditions. In our opinion, economic thinking is still very largely related to traditional Cartesian (and Newtonian) concepts of science.

The Cartesian mechanism of thinking, although effective and influential in situations where industrialization is the top priority and the best tool for organizing wealth and welfare, has raised a series of methodological and practical problems. Isolating monetarized economic factors is a method that is today showing more and more weaknesses. In order to clarify this point, consideration will first be given to the way the notion of science is often perceived in economics.

It was customary in the nineteenth century to believe that the Cartesian or Newtonian method of scientific research consists first in defining a situation or a problem clearly, identifying and measuring all its constituents, as if the said situation or problem could be fully determined (or at least assuming that anything left out had no appreciable influence on the system under observation). In this way, a water molecule can be isolated and studied. In this way, Newton gave a clear view of celestial mechanics. In this way, the economist hoped to provide scientifically framed and determined "models" of reality. In practice, this is often still the simple - even trivial - method used and still conceived in accordance with the underlying assumption that the reality examined is for the most part "objective". This view presupposes simple systems and, as an essential corollary, the divisibility of time and space.

It has been clear in the natural sciences for many decades that even if a multitude of realities exists which we can profitably research in the "Cartesian" way, when we get down to basic issues (such as: What is matter ?) and to issues related to "objectivity" (if such a thing exists), we find ourselves in extremely complex and even indeterminate systems. ${ }^{7}$

It has been rather surprising to note during recent decades that while "social" scientists of all kinds - economists in particular - have been chasing after an " objective" image of their "science", and have often implied that science would in

7 Indeterminate used in the sense of Heisenberg. The whole controversy, started by Einstein with his "probabilistic" reality, is an important reference for this point. 
this way come one day to bear comparison with the "more scientific" nature sciences, the latter have in the meantime partially reversed the picture. ${ }^{8}$

The consequence of this for economics and social sciences in general, is that their validity is essentially restricted to given (historical) situations and that the word " universal" validity (in time and space) does not mean very much.

If what has been said here is only partially acceptable, it none the less follows that it may benefit economics to call some basic assumptions in question, especially the notion of value, on which economics itself is founded, and its historical and cultural determinants with reference to the notions of time and space. ${ }^{9}$

As for the traditional limitations of the notion of value in space, the idea has already been put forward by us that space assumes the existence of a structure for the production of wealth and the promotion of welfare that has in point of fact been by-passed by post-industrial society : it is less and less useful to divide the economy into primary, secondary (industrial) and tertiary (services) sectors, and more and more rewarding and "practical " to verify final results achieved by the integration of various economic activities. ${ }^{10}$ Furthermore, the interdependence of monetarized and nonmonetarized activity should be more adequately appreciated and accounted for. But even more important observations should be made with regard to the notion of time :

- in the Cartesian/Newtonian universe, time is either infinite or specific: one can isolate a moment in time. One can statically examine "reality" as if it were $a$ picture, freezing all movement. The equilibrium of the universe of Newton is like the equilibrium of the supply/demand curves of the economists : at a given moment in time (instant time) the situation is such and such. Simple, definable forces determine equilibrium situations, and each state or situation can be isolated.

Under such conditions, the relative behaviour of phenomena in time and space tends to disappear, or to be represented in a static and inadequate framework.

At this point it has to be recognized that the activity of the insurance industry represents a very interesting situation in which the equilibrium of supply and demand (the price of an insurance policy "today" and the cost of a damage "tomorrow" covered by the policy) is a matter of real, uncertain time. Duration of time (how long) and space (the statistical universe) must be taken into consideration.

It is easy to appreciate in this case how deep-rooted are the causes that have until now prevented insurance (and services in general) from being considered as important as the industrial activities of production (the latter being more easily reduced to a

8 To the point where a Nobel prizewinner like Prigogine now sees a possibility for a " new alliance" between human and natural sciences. These are no longer different in kind: they are simple more or less indeterminate [4] and [15].

9 More basically it is maintained here that the notion of "value added" has grown more and more insignificant as a yardstick for the measurement of "additions" to wealth and welfare. In some cases, it measures subtractions or deduction from wealth. On the notion of "deducted value", see [4] and [5].

$10 \mathrm{See}$ in [4], the analysis of the post-industrial society, chap. 1 and 2. 
static framework, although this is also more and more inadequate because of the increasing "lead" times in modern technology). Among other things, Irving Pfeffer has shown that the analysis of risk, particularly of insurance risk, requires a dynamic analysis framework, whereas economic theory has chosen a static method of analysis. (See [13] and [14].)

Thus in economics the notion of value is static (value given at a moment in time, in particular at the moment of exchange). Therefore, in the image of any given model, which in economics seeks to be photographic, several important factors are excluded :

- not only is the probabilistic evolution of economic behaviour dismissed (as in physics before the 1920s) to the point where the majority of economic models imply the "certainty" assumption. (Sometimes this is said to be done for the sake of simplification.)

- but also any economic behaviour covering any length of time disappears : in the national accounting of insurance, only the employees in the insurace companies are accounted as " added value" (they are paid "now" as in any other sector, which means in practice every month - a short period of time ${ }^{11}$ ). The real value of insurance, the increase in wealth brought about by the possibility of controlling future probable damage by means of the insurance system has no "value"...

Economists have had to invent a trick to get rid of this contradiction. They speak of "transfers" and the logic is the following: when a house burns down, insurance will pay for its reconstruction (if it was insured). The action of building is real added value and such will appear in future statistics as an increase of industrial activity. Therefore, there should be no need to calculate insurance as value - they say - for it merely organizes financial transfers. What is "productive" is the act of building, whereas the act of making that building possible is, awkwardly, " non-productive": the old scheme has been saved.

In point of fact, in the case of a house that burns down, what happens in real time and in terms of real wealth is as follows :

- when the house is built it is accounted as an added value, which is only right and proper ;

- when it burns down, the level of real wealth is reduced (a deducted value is produced, or a negative added value), but no macro-accounting takes this into consideration ;

- when the house is rebuilt thanks to its having been insured, the economic accouting systems register the fact that a new (industrial) added value has been produced. This suggests, by the way, the absurd idea that the greater the amount of fortuitous destruction, the more chances there are of increasing value added. The correction for this is to take into account the deducted value, too ;

11 Static time and short time are not the same thing of course, but a "short time" reality allows in practice a "static" analysis, whereas static analysis is useless for long-term phenomena. 
- the rebuilding of a house thanks to an insurance policy is a value that could be ascribed totally to insurance activity. The house might not have been rebuilt without insurance. In this case, the industrial tools are part of the security mechanim (or service) provided by insurance.

The traditional economist would say that insurance is paid for its service, which is the organization of the transfer of money (through the activity of insurance employees and office equipment) and that the money spent on the rebuilding of the house is again an industrial activity, producing an industrial added value. But this is obviously untrue, at least from the standpoint of the buyer of the insurance, since he buys the possibility of rebuilding the house and not the service of a financial transfer alone. And he buys this possibility from an insurance company, just as the buyer of a chemical plant very often buys the services that go with it, which are not distinguished as non-industrial.

Indeed, the problem is not a matter of giving priority today to service industries over industrial producers, but of recognizing the integration of the two (and of agriculture) in the production of wealth in a way that is different from the way wealth was produced in the period of the industrial revolution. It could be said that, in practice, the traditional concept of value isolates and gives priority to industrial activity proper, whereas what is proposed here is a new concept of value corresponding to a postindustrial society in order to facilitate the adaptation of the tool of economic thinking to the contemporary economic situation, in which industrial and service activities are at the same level (see appendix 1).

When insurance and service activities represented a relatively small part of the economy, this had no great practical effect, especially when the economy was in the upper phase of the industrial revolution. In such a situation, the argument submitted here could be dismissed as intellectual hair-splitting.

The position is different in a post-industrial environment where people at least begin to feel that their wealth and welfare are increasingly dependent on mechanisms that make things possible and accessible, rather than on simple acts of production. ${ }^{12}$

The following example will clarify this point with regard to changes in the economic structure :

After the 1929 slump, many poor people could not obtain food because they lacked money. Food was also destroyed so as not to flood the market and lower prices (thus putting more industries out of business). Keynesianism had its origin in situations of this sort : if people could simply get more money (even by deficit spending) they would buy the existing surplusses. Instead of destroying supply it was clearly better to stimulate demand.

12 At this point, it would be also very useful to open a debate on the notion of stock and flows in the accounting of wealth. See [4], chap. 3 . 
At the present time, all governments have learnt - in one way or another the Keynesian recipes, so that inflation is one of the few certainties of our time (whereas during most of the industrial revolution, deflation was the most recurrent phenomenon). But we still have more and more cases of over-production, particularly in agriculture. Farmers quite often jettison tomatoes, fruit, vegetables, along the highways. Does this mean that people have no money to buy these products? Obviously not.

The problem is not production, but the cost of access to production. Such costs are linked to the tertiary sector (services of all sorts), and in every case they are higher than the costs strictly related to production : distribution and service costs command the price equilibrium. Clearly, economic value is related nowadays to a complex system heavily dependent on the ways and means of access to a product (or rather its services) : we are in a post-industrial society, a service society.

Of course, insurance is only a part of available services, and not even the greater part in absolute terms. But it is very important and in many cases growing more than proportionately so.

Furthermore, of all service activities, insurance is shown by experience to be the one most closely linked to the management of economic problems in time, under probabilistic assumptions.

If agriculture was the key reference point of Quesnay and of many later economists, if industry has been the key reference point of economic theory up to now, there is reason to believe that in studying the activity of insurance, economists should find an excellent reference point for the definition and rethinking of post-industrial economics. Discussion of the notion of value brought to the fore by risk and insurance-related institutions might be a tool for thorough and interesting research on what, today, adds to economic wealth and welfare and how economic strategies can be improved.

Enlarging on the implicit and exclusive paradigm of economic theory, still predominantly connected, as it were, to the industrialization process, may contribute towards a more positive view of what future wealth and welfare could be.

\section{Risk management and Insurance}

We shall now consider the relevance of insurance to present and future development of economic theory from another, complementary angle, dealing with the more fundamental reasons for the success of the notion of "risk management" during the last few decades.

Up to about twenty years ago, the notion of risk could be easily split - the Cartesian way - in two directions : on the one hand, the "entrepreneur's risk" of 
finding new markets and investing in new products or technology ; on the other, the "pure risk", as dealt in by insurance, concerning specific individual or institutional vulnerabilities.

The former has been analyzed by leading economists such as Schumpeter and Knight ; the latter has found a small place in manuals on economics, usually in the appendix or in notes at the bottom of the page.

When industrialization was at its peak, this sequence of priorities could be observed in practice within industrial companies. With the exception of manufacturers of certain dangerous products (such as explosives), companies, in the main, dealt with the insurable type of risk at a very low level and almost never at Board or executive level ; they were "entrepreneurs" par excellence mainly handling "entrepreneurial" decisions, i.e. " risks".

Today, it is sufficient to consider, in most industrial companies, the importance attached to vulnerability risks by these same Boards or Managements. Whether it is a chemical product, an electricity supply plant, an offshore enterprise involving the investment of several billions of dollards, or a plant vulnerable to indirect losses linked to complex technological systems, or a product liability issue, the survival and development of economic undertakings require an ever greater control of risks, including those due to increased vulnerability. The entrepreneur today, by reasons of urgency or priority, is obliged to merge his management schemes with whatever type of risk is relevant for his successful future, regardless of whether it is "entrepreneurial" or "pure ". Usually, such risks have to be included in a general strategy. The same applies to investment : the vulnerability level is more and more determinant in investment considerations.

This situation is clearly apparent in the rapidly increasing number of cases in which managers of industrial firms feel the need to enlarge their field of activity, not only by subscribing to insurance policies, but also by analyzing and controlling all security measures and costs in an over-all cost-benefit analysis. The next step is when some of the risks dealt with at this level are subject to discussion and/or revision at top level, because of their implications and relevance for the over-all strategy of the company. Of course, top-level executives have themselves become concerned about vulnerability risks when necessary, with or without prompting from the risk managers.

This does not mean that insurance must cover risks other than pure ones, but that the coverage of insurable risks implies in an increasing number of cases a series of analyses, a level of understanding of the general risk situation where optimization by the entrepreneurs includes, in economic terms, all types of risks.

This is what risk management means : it is basically the new definition of risk corresponding to post-industrial society. Discussion and action concerning risk management represent the reaction of those who, in practice, live and experience the consequences of an important general modification of economic patterns, who live and experience the issues of post-industrial economics in their everyday lives.

In more general terms, we are now in a situation in which the assumption of a static economic world, if it is sometimes "practical" from the point of view of the 
economist, makes less and less sense in an environment of growing uncertainty, in which the interdependence of pure and entrepreneurial risks adds to its complexity, not to speak of the number of cases where pure risks themselves become uninsurable.

\section{The future of economics : uncertainty and value}

Today, not only has the notion of uncertainty become a "fact of life", linked to specific perceptions or a particular business cycle, but ever since Einstein had to admit implicitly - against his will and deep moral conviction - that God " plays with dice", there has been as well a constantly growing volume of literature dealing with fundamentals concerning the nature of science and the structure of knowledge. Basic notions are more and more under scrutiny such as relative time/space, the indetermination of systems, the historical relativity of axioms, and uncertainty, all through the natural and social sciences spectrum. ${ }^{13}$

Contrary to what happened in the past century, during which science was considered to be something like a more efficient way of attaining " universal" truth and as such, as a competitor to religion - it is now generally accepted that science is a method of "falsifying" (in Karl Popper's terminology) all theories, hypotheses and facts. In other words, there is no such thing as " universal " scientific truth, but only a limited operational validity in time and space of any scientific law or theory (which means that "it works").

Our culture, by and large, is not yet used to looking at science in this way. It is very revealing to find even in recent literature the survival of the " universal objectivity" notion of science. A brilliant example is "The Sleepwalkers" by Arthur Koestler, in which science and religion are treated as complementary ways of reaching(?) universal truth. In our opinion, underlying these attitude to truth and science is the notion of time/space. If time/space is considered to be something that can be isolated in a given moment or place, this "abstract" moment (like Newton's notion of the universal equilibrium) can be logically considered to be of "universal" value. ${ }^{14}$ But this pretension to "universal" logic breaks down when mathematics tells us that there are no more " universal ", unchangeable (Godlike) axioms.

Economics itself has developed for more than a century against this cultural background of a "static", Newtonian notion of time/space.

Static time/space is also compatible with the assumption of certainty, which is today still dominant.

13 Quite interesting and accessible to non-specialists are the book by Kline [7] and a short article by Little [9] giving a straightforward explanation of the relative truth of mathematics. In the field of physics, see Bohm [1].

14 For a clear description and analysis of this point, see Clark [2]. 
The notion of uncertainty has, however, made some important inroads in economic thinking at this stage, i.e. keeping the reference to static time/space essentially unchanged. This has happened in two main ways:

- the first derives from the notion of subjective value (see Hicks [6]), and has to do with the risk-averse or risk-prone behaviour of individuals. In this connexion, economics becomes more and more a behavioural science competing with psychoanalysis, psychosociology, etc. It tends also to dispense with economic analysis in terms of demand management and overlook the non-psychological conditions for the production of supply. In this connexion also, through belief in the power of science and technology, it is diverted from much needed empirical research on how and when they potentiate supply ;

- the second way has been through the consideration of uncertainty as being due to a lack or "asymmetry" of information in a system which "for the sake of convenience" remains always essentially static. ${ }^{15}$

These two main ways are promising and stimulating and will probably make a valuable contribution to economic knowledge and to the integration of the various economic activities according to their way of dealing with uncertainty.

It would seem also that a major break through will come with the adaptation to economics of the nations of real space/time dimensions, which implies the taking into account of real and relative duration. This process has already virtually begun. It calls in the first place for the definition and acceptance of a new notion of value. ${ }^{16}$

In general terms, it should be recalled that life itself, real life, is based on uncertainty. It is not as a choice, but as a condition that risk and uncertainty characterize life, if only because life is real time, and risk and uncertainty are connotations of real time.

René Passet, an economist, has recently written a book [12], in which he shows that economics has until now been essentially concerned with "dead things". He starts his analysis by drawing attention to the correspondance between economic thinking during the past two centuries and changes in the notion of science. ${ }^{17}$ The opposition he points out between dead and living things is analogous to the opposition between static and real time. The transition from the one to the other is a transition from utopian certainty to the challenge of real uncertainty, from essentially deterministic thinking to the possibility of building real responsibility and freedom, taking advantage of a largely indeterminate world.

15 See Diamond and Rothschild [3], chapters "Individual choice in a static setting", "General equilibrium in a statis setting", "Sequential choice and equilibrium with limited information".

16 This is precisely the type of dialogue that the Report on Wealth and Welfare [4] has tried to initiate.

17 His verification of the economic paradigms with the work of Ilia Prigogine is very promising. 
Of course, too much uncertainty leads to impotence, which is precisely the reason why its origin must be understood whenever possible (as in the case of understanding that the present rigidities of economic supply are conditioned by the diminishing returns of technology). But in the end, the problem is how to live better, which is to face risks better.

The present state of great uncertainty in most of the contemporary world might lead some to despair. But at the level of action, it is also a very great challenge to culture, science and economic theory.

\section{Appendix 1}

A schematic description of the evolution of the production structure and of the notion of value

1. Value in classical economics

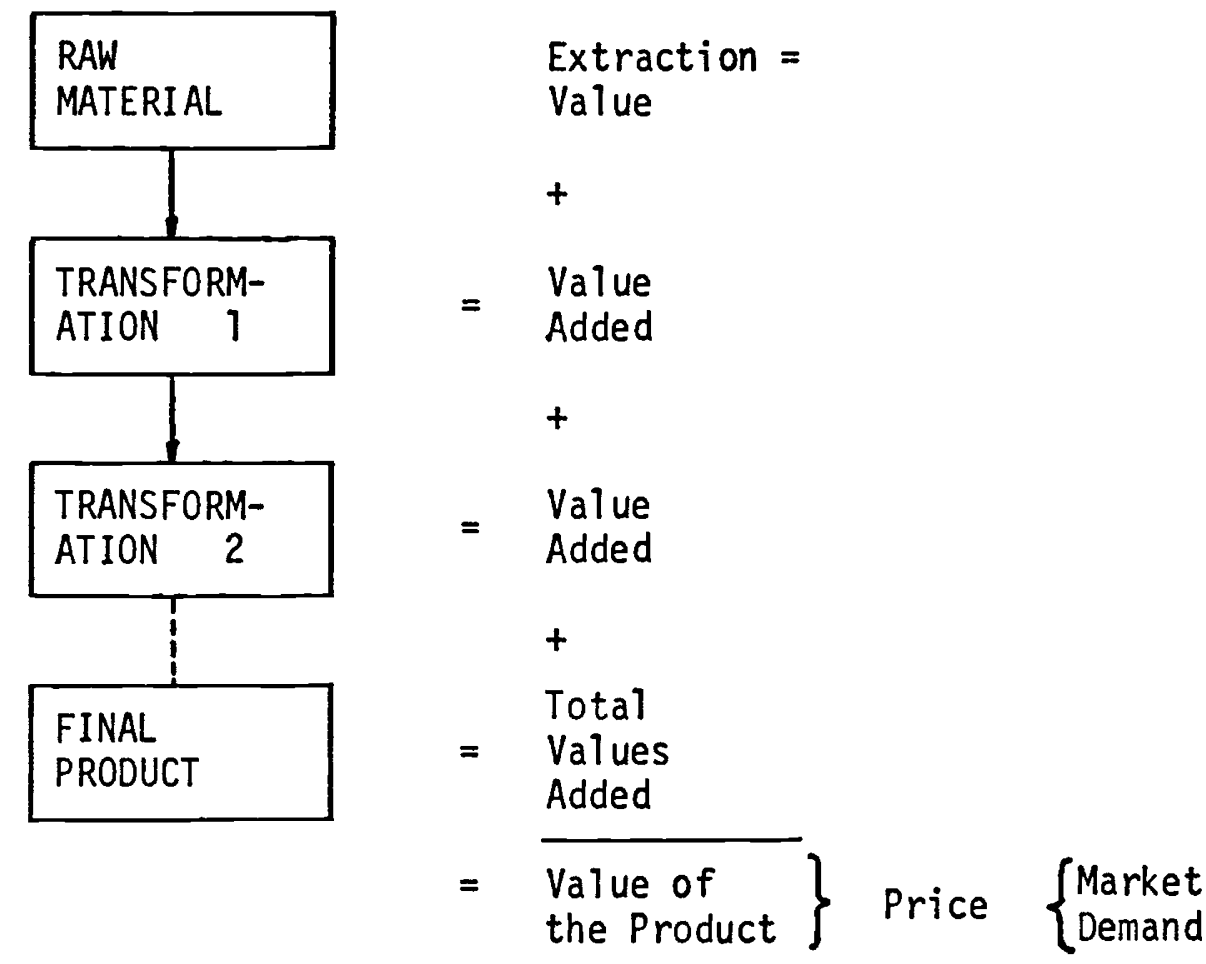


For any production, we start from the raw material : this has no value in itself. The value of this raw material is commensurate with the cost of extracting it. The raw material passes through one or more phases of transformation before becoming a final product. At each phase there is a value added which represents the cost of the additional labour used.

The price set by the market (for simplification, at the level of the final product), is the element of measurement which will be the reference for qualifying value.

From this notion of value, classical economics will develop the notion of capital and of the productive function.

2. Services and maintenance become an important part of the "production" system

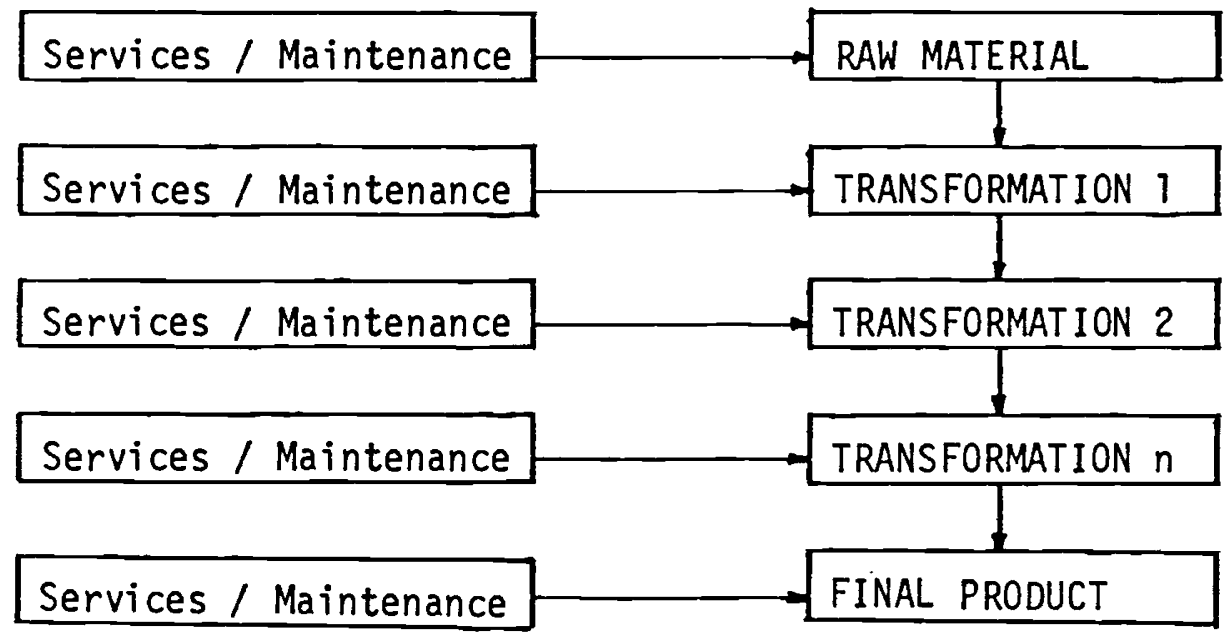

It is essential to note that these service activities are accomplished both internally and externally to the production system. This is an obvious remark; but it clashes with the traditional, classical economic separation of productive activities. Services are considered only as a separate part (often either insignificant and/or unproductive) of the economy.

3. Furthermore, waste increases to such an extent that it becomes a heavier and heavier cost

We propose a more complex diagram.

On the right side of the diagram, we can easily imagine how waste is produced at each stage of production. 
This phenomenon has always existed. But, as long as it was of little importance (either by itself, or because the non-monetary economic system outside it was capable of taking care of it without much damage), it is clear that the attention of the economist, as well as that of the entrepreneur, could be limited to the central production line.

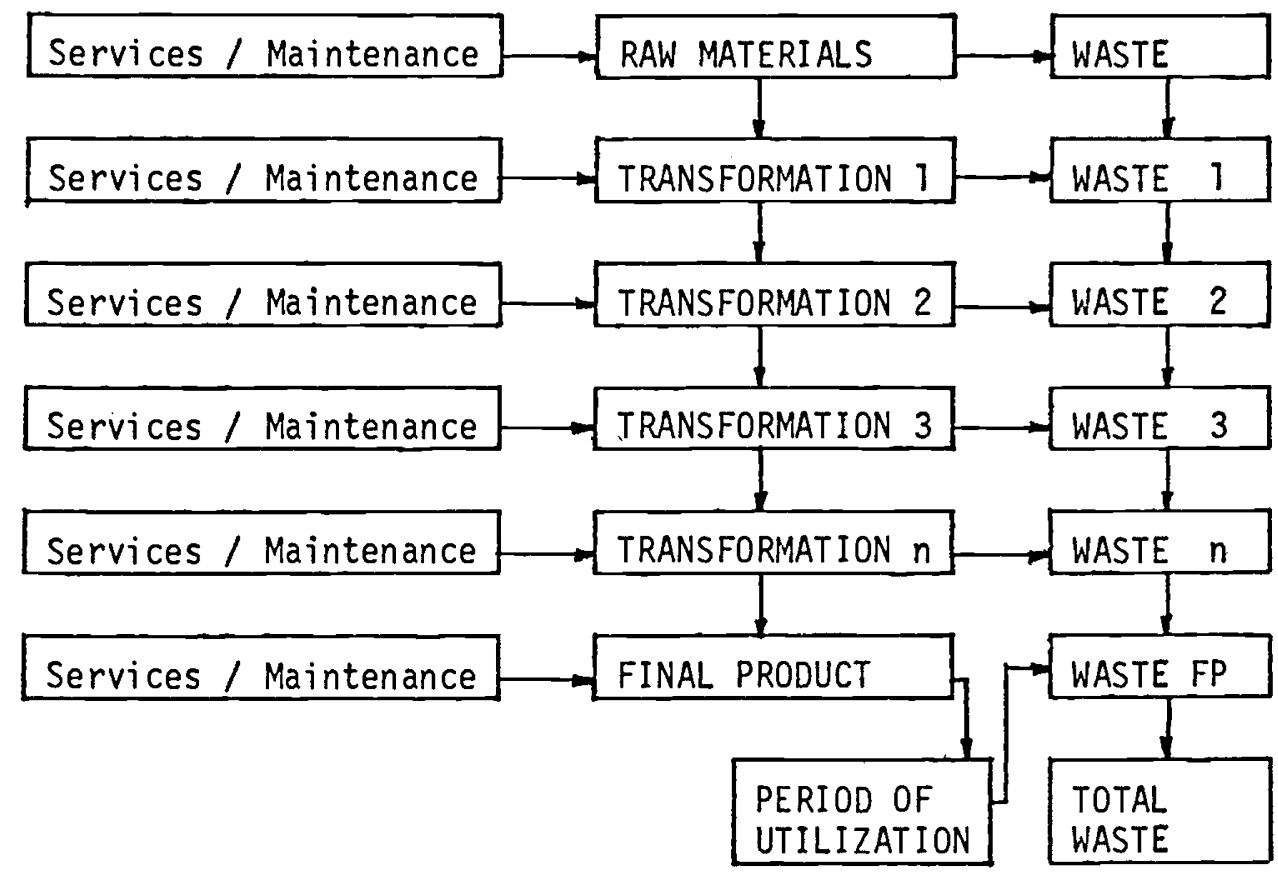

Now, this additional factor adding to the complexity of the industrialization process has to be taken into account in order to see if the system of production is still essentially a system of production.

Also the final product, after a period of utilization, becomes waste.

If we look therefore at this table not as a static picture of a situation in a moment in time, but taking into consideration real time, we can consider this graph as the description of a process through which a certain quantity of Raw Materials (RM) has been transformed into a certain amount of waste (Total Waste).

Of course, a lot of this waste will then be recuperated and reintroduced into the system as Raw Material. 
We therefore have here a notion of value which depends on the period during which a product or a service (which represents a stock of services) is useful and usable : in other words it represents a utilization value.

In this case all processes and activities contributing to the utilization value are costs which intervene before, during and after the period of utilization of the product or service :

- production,

- distribution,

- storage,

- repair and maintenance,

- servicing,

- replacement,

- damages,

- financial costs,

- insurance,

- cost of disposal.

In this case, the contribution of insurance to the utilization value is on the same level as the production (and other) costs, which are all essential to the production of value.

In the notion of classical economics, value is first of all related to industrial production. Insurance is secondary ; often it is even considered as not producing economic value at all.

The notion of risk changes from a simplified notion of the risk of the entrepreneur, who tries to optimize production chances, to the more complex notion of Risk Management, where the gain is linked to the optimization of all the factors (costs) contributing to the utilization value. 
Appendix 2

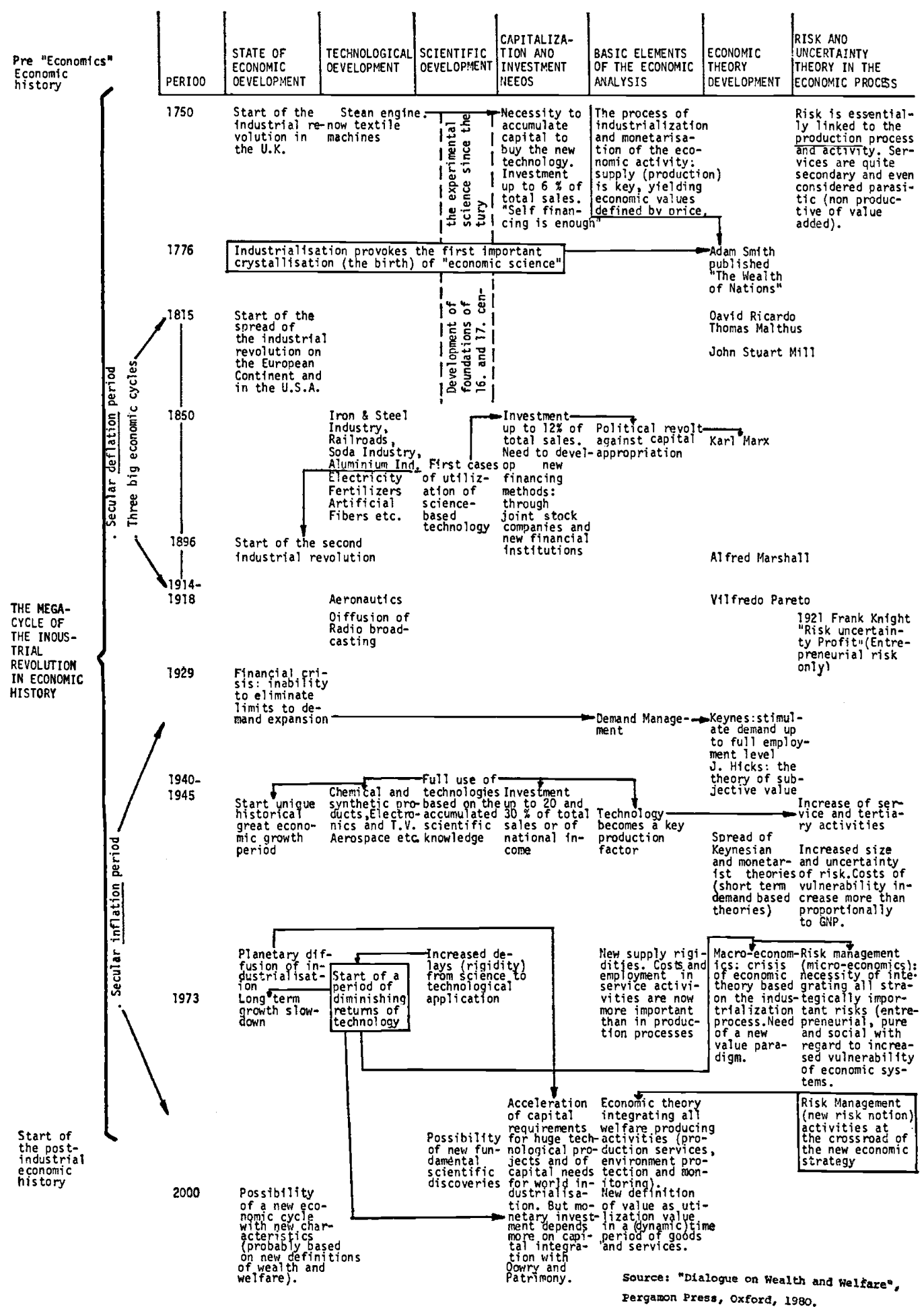




\section{REFERENCES}

1. BOHM, D.: Wholeness and the Implicate Order, Routledge \& Keegan, London, 1980.

2. CLARK, R. W. : Einstein, the Life and Times, Hodder \& Stoughton, London, 1973.

3. DIAMOND, P., and ROTHSCHILD, M.: Uncertainty in Economics, Academic Press, New York, 1978.

4. GIARINI, O.: Dialogue on Wealth and Welfare, Pergamon Press, Oxford, 1980.

5. GIARINI, O., and LOUBERGE, H. : The Diminishing Returns of Technology, Pergamon Press, Oxford, 1978.

6. HICKS, J. R. : Value and Capital, Oxford University Press, 1939.

7. KLINE, M. : Mathematics - The Loss of Certainty, Oxford University Press, 1980.

8. ILLICH, I.: "Shadow-Work", paper presented at a conference in Kassel, September 1980.

9. LITTLE, J.: “The uncertain craft of mathematics", New Scientist, 88 (4 December 1980), 626-628.

10. MARSHALL A.: Principles of Economics, Mac Millan, London, 1977 (eighth edition reprinted).

11. MAYER, T.: "Economics as a hard science: Realistic goal or wishful thinking ?", Economic Inquiry, 18 (April 1980), 165-178.

12. PASSET, R. : L'Economique et le Vivant, Payot, Paris, 1979.

13. PFEFFER, I. : Insurance and Economic Theory, Irwin, Homewood (Illinois), 1956.

14. PFEFFER, I., and KLOCK, D. R. : Perspectives on Insurance, Prenctice Hall, Englewood Cliffs (New Jersey), 1974.

15. PRIGOGINE, I., and STENGERS, I. : La Nouvelle Alliance, Gallimard, Paris, 1979.

16. SMITH, A.: The Wealth of Nations, Penguin Books, Hammondsworth (Middlesex), 1977 (first published 1776).

17. WEISSKOPF, W. A.: "The method is the ideology: From a Newtonian to a Heisenbergian paradigm in economics", Journal of Economic Issues, 13 (December 1979), 868-884. 